\title{
DESENVOLVIMENTO DE MATERIAL MULTIMÍDIA NO ENSINO DE BIOLOGIA
}

\author{
Marlene Benchimol | marlenebenchimol@gmail.com \\ Doutora pela UFRJ em Ciências (Biofísica). Professora de Biologia Celular pela UFRJ e professora titular da Universidade Santa \\ Úrsula. Docente concursada da Fundação CECIERJ.
}

Marianna Augusta Ferrari do Outeiro Bernstein | outeirobernstein@yahoo.com Doutora em Ciências pela Universidade do Estado do Rio de Janeiro - UERJ. Acadêmico IV/Desenhista Instrucional - Web Biologia da Fundação CECIERJ.

Rodrigo Alcantara de Carvalho | rodrigo.cederj@gmail.com

Mestre em Ciências pela Universidade Federal Rural do Rio de Janeiro - UFRRJ. Acadêmico III/Desenhista Instrucional - Web Biologia da Fundação CECIERJ.

Dirceu Esdras Teixeira | esdras@bioqmed.ufr.br

Doutorando em Educação, Difusão e Gestão em Biociências pela Universidade Federal do Rio de Janeiro. Acadêmico IV/Desenhista Instrucional - Web Biologia da Fundação CECIERJ.

\section{Resumo}

Apresentamos uma metodologia de produção de aulas multimídia para estudantes do curso de Licenciatura em Ciências Biológicas, na modalidade semipresencial. Nosso método tem como base um conteúdo disponibilizado sob a forma de animações interativas. Através de uma navegação linear, o aluno possui pleno controle do andamento da aula, tendo como estímulos a riqueza visual e a interatividade, permitindo caminhar no seu próprio tempo até a completa compreensão do conteúdo. Este conteúdo se apresenta em uma linguagem coloquial simulando a presença de um professor competente e simpático, além de descomplicado. Toda a estrutura da aula é fundamentada no construtivismo e no cognitivismo e cada um dos aspectos envolvidos na produção do material multimídia, como cores, tipografia, animações, analogias e bom humor são utilizados como estratégias motivadoras e facilitadoras do processo de aprendizado. Uma equipe especializada na produção gráfica, acompanhada de pós-graduados em biociências, revisores de português e de conteúdo produz cada aula, discutindo aspectos relevantes do ensino-aprendizagem. O resultado é um material multimídia rico, disponibilizado em CD e/ou online, que permite que o aluno aprenda sozinho.

\section{Palavras-chave}

Biologia. Ensino a distância. Aulas pela web. Animações no ensino de Biologia. 
DEVELOPING MULTIMEDIA MATERIAL FOR TEACHING BIOLOGY

\section{Abstract}

Here we present a method for producing multimedia lessons for Biological Sciences distance undergraduate students, based on content presented in an interactive animation form. Through linear navigation, the student has full control of the lesson's progress, with the aid of visual richness and interactivity, enabling progress in his own time, until full mastery of the content is achieved. The material is presented in colloquial language, simulating the presence of a competent, friendly and straightforward teacher. The entire class structure is based on constructivism and cognitivism and each aspect involved in the production of multimedia material, such as color, typography, animation, analogies and humor, is used as a motivational and facilitating strategy for the learning process. A graphic production team, assisted by life sciences graduates and editors of Portuguese and of content, produces each class, discussing relevant aspects of teaching/learning. The result is a rich multimedia material, available on $\mathrm{CD}$ and/or online, which allows the student to learn on his own.

\section{Keywords}

Biology. Distance learning. Online classroom. Animation in Biology teaching.

\section{Introdução}

O desenvolvimento tecnológico e cultural que vivenciamos atualmente torna evidente a necessidade de reinventar a forma de ensinar e aprender. Educar com novas tecnologias é um desafio que demonstra cada vez mais a necessidade de ser enfrentado com profundidade.

O surgimento de novas tecnologias da informação e computação nos processos de mudança social $e$ cultural no cenário da sociedade apresenta consequências tanto para a prática docente como para o processo de aprendizagem.

\subsection{EAD}

A Educação a Distância (EAD) vem se apresentando como uma modalidade alternativa de aprendizagem, que utiliza novas Tecnologias de Informação e Comunicação (TICs) como possibilidade de interação no ambiente virtual. As múltiplas possibilidades de relações presentes na rede potencializam uma "nova relação com o saber" (LÉVY, 1999).

Assim como Roberts detectara em 1996, o número de instituições que oferecem algum tipo de educação a distância no mundo ainda cresce constantemente.

No Brasil, a educação a distância alcançou, com a Lei 9.394, de dezembro de 1996, o status de modalidade plenamente integrada ao sistema de ensino. A Lei de Diretrizes e Bases legitimou a Educação a Distância, conferindo aos cursos a distância valor legal equivalente ao dos cursos presenciais.

Atualmente, o Brasil possui 207 instituições credenciadas junto ao MEC para Educação a Distância, sendo que 88 destas instituições se encontram na Região Sudeste, organizadas em 2.131 polos de apoio presencial (SIEAD, 2009).

\subsection{A Fundação CECIERJ e o Consórcio CEDERJ}

No Estado do Rio de Janeiro, há 22 instituições organizadas em 333 polos de apoio presencial (SIE$\mathrm{AD}, 2009)$; dentre estas instituições está um consórcio que reúne o Governo do Estado do Rio de Janeiro através da Fundação Centro de Ciências e Educação a Distância do Estado do Rio de Janeiro (CECIERJ) e as seis universidades públicas sediadas no Estado: a Universidade do Estado do Rio de Janeiro (UERJ), Universidade Estadual do Norte Fluminense Darcy Ribeiro (UENF), Universidade Federal do Estado do Rio de Janeiro (UNIRIO), Universidade Federal do Rio de Janeiro (UFRJ), Universidade Federal Fluminense (UFF) e a Universidade Federal Rural do Rio de Janeiro (UFRRJ).

A elaboração do Consórcio CEDERJ ocorreu em 1999, através de uma comissão formada por dois membros de cada universidade junto à Secretaria de Estado de Ciência e Tecnologia (SECT). A assinatura de um documento pelo governador do Estado do Rio de Janeiro e pelos reitores das Universidades Consor- 
ciadas, no dia 26 de janeiro de 2000, efetivou a consolidação dos alicerces do Consórcio CEDERJ.

O consórcio CEDERJ vem servindo de modelo em todo o Brasil, inclusive inspirando ações do MEC no fomento ao Ensino Superior a Distância e à Universidade Aberta do Brasil (UAB). O consórcio faz parte da Fundação CECIERJ, juntamente com a Divulgação Científica e a Extensão.

$\mathrm{O}$ CEDERJ, aliado às prefeituras municipais que sediam polos regionais, objetiva contribuir para a interiorização do Ensino Superior público, gratuito e de qualidade no Estado do Rio de Janeiro, aumentando a oferta de vagas em cursos de graduação e pós-graduação e valendo-se da Educação a Distância, que permite o ingresso de indivíduos excluídos do processo educacional superior público pela dificuldade de acesso ou pela indisponibilidade de tempo para cumprir com os horários tradicionais de aula.

No Consórcio CEDERJ, a competência acadêmica dos cursos está a cargo dos docentes das universidades, que preparam o projeto político e pedagógico dos cursos, o conteúdo do material didático, cuidam da tutoria e da avaliação.

A Fundação CECIERJ é responsável pela produção do material didático, pela gestão operacional da metodologia de EAD e pela montagem e operacionalização dos polos regionais.

No contexto específico da produção de material didático, as pesquisas demonstram que cada vez mais os alunos almejam uma experiência de aprendizado interativo, que integre diferentes mídias.

\subsection{O estímulo visual na EAD}

Historicamente, podemos perceber que a educação enfatiza o aprendizado verbal enquanto o interesse no aprendizado visual é deixado para trás. Mas hoje em dia, a quantidade de informação adquirida através de meios visuais, a habilidade de compreender, avaliar e produzir representações visuais se tornou de grande importância na educação (FERK et al., 2003).

Segundo Mayer et al. (1996), as representações visuais são capazes de atrair a atenção e manter a motivação, provendo um meio adicional de representar a informação e uma forma mais rápida de ob- ter o conhecimento que não pode ser vislumbrado utilizando-se somente do texto. Mathewson (1999) considera as representações visuais fundamentais na comunicação de conceitos científicos, por proverem formas de tornar visíveis fenômenos que não podem ser observados a olho nu. Buckley (2000) caminha ao encontro deste pensamento, afirmando que as representações visuais ilustram fenômenos invisíveis ou abstratos que não podem ser observados ou experimentados diretamente.

O trabalho de Peeck (1993) é mais específico ao considerar que as representações visuais aumentam a retenção da informação associada ao texto, e Roth et al. (1999) vai além, ao considerar que tais representações visuais aumentam a solução de problemas e facilitam a integração de novos conhecimentos com conhecimentos previamente adquiridos.

Pesquisas têm demonstrado que animações computacionais podem facilitar a aprendizagem dos alunos para diversos temas de grande complexidade (SANGER et al., 2001).

\subsection{Nosso objetivo}

No nosso trabalho, buscamos produzir aulas baseadas em objetos de aprendizagem que combinando animações, textos, ilustrações, fotografias, clipes de vídeo, som, descrições de hipertexto e links de atalho para a internet tornam-se verdadeiramente um recurso multimídia.

Nosso desafio é buscar uma ampla interação entre o aluno e o objeto de aprendizagem, motivando-o com animações de fácil navegação, atividades interessantes, interatividade, usabilidade e design envolvente, de forma que os objetivos educacionais possam ser alcançados.

Este trabalho objetiva apresentar os passos necessários para a produção de um material de uso didático para a Web, onde elementos essenciais devem ser respeitados, como a linguagem visual e escrita, temporalidade, qualidade das imagens, adequação de cores, seguimento das etapas necessárias para a consolidação de aprendizagem, utilização de conceitos reais já vivenciados pelo aprendiz, utilização de analogias e exemplos práticos, entre outros importantes elementos. Vamos, a seguir, apresentar 
como trabalhamos na Web para a produção de aulas de Biologia para cursos de graduação em Ciências Biológicas a distância. É importante enfatizar que os conceitos básicos aqui apresentados podem ser utilizados em qualquer outro tipo de ensino, seja de Matemática, Física, Química ou Pedagogia.

\section{Metodologia}

\subsection{O elemento humano}

$\mathrm{Na}$ Fundação Centro de Ciências e Educação Superior a Distância do Estado do Rio de Janeiro produzimos aulas para alunos de graduação, tanto online, como em CDs. Para o processo de produção das aulas de Biologia para EAD contamos com uma equipe multidisciplinar da qual fazem parte professores universitários de áreas específicas, designers e pessoal de apoio, tal como revisores de conteúdo e de português (Tabela 1). A instituição tem desenvolvido ao longo dos anos material didático para Web com qualidade de imagem e um design visual envolvente.

Nossa experiência demonstra que algumas características são fundamentais para quem pretende trabalhar na produção de material didático multimídia, tais como: criatividade, inovação, responsabilidade, comprometimento, transparência, espírito de integração $e$ abertura a trocas de experiências. Uma das principais formas de desenvolvimento da equipe ocorre através de cursos internos de atualização e capacitação, que envolvem diversas áreas e profissionais ligados ao processo de produção.

\subsection{O coordenador da equipe}

Cabem ao coordenador do projeto o planejamento e a organização da infraestrutura e das equipes de projetos de $\mathrm{EAD}$, planejamento das aulas, aprovação e ajustes dos objetos de aprendizagem, discussão e aprovação do storyboard (roteiro) do desenhista instrucional. Também cabe ao coordenador resolver problemas de ordem administrativa e manter contato com especialistas de conteúdo das áreas específicas (adhocs) para aprovação do material final, além de outras atribuições.

Perfil desejável: doutorado na área em que coordena; prestígio para obtenção de verbas junto a agên- cias financiadoras para apoio ao projeto, capaz de estimular a equipe a realizar o seu melhor e saber selecionar novos membros para a equipe que sejam competentes; promover treinamento constante para a evolução de novas técnicas; boa interação com os superiores e coordenados.

Tabela 1: Resumo do perfil de uma equipe de produção de material Web com a principal função de cada cargo.

\begin{tabular}{|c|c|}
\hline CARGO & FUNÇÃO \\
\hline $\begin{array}{l}\text { Coordenador } \\
\text { Planejamento }\end{array}$ & $\begin{array}{l}\text { Orientação e desenvolvimento } \\
\text { instrucional de material } \\
\text { didático voltado para EAD }\end{array}$ \\
\hline $\begin{array}{l}\text { Roteirista ou desenhista } \\
\text { instrucional }\end{array}$ & $\begin{array}{l}\text { Desenho instrucional das } \\
\text { aulas Web }\end{array}$ \\
\hline Webdesigner (animador) & $\begin{array}{l}\text { Produção de animações 2D } \\
\text { e 3D }\end{array}$ \\
\hline Webdesigner (HTML) & $\begin{array}{l}\text { Inclusão das animações na } \\
\text { página em HTML }\end{array}$ \\
\hline Ilustrador & $\begin{array}{l}\text { Realizar ilustrações no } \\
\text { computador }\end{array}$ \\
\hline Revisor de português & $\begin{array}{l}\text { Revisão do conteúdo das aulas } \\
\text { Web }\end{array}$ \\
\hline $\begin{array}{l}\text { Analista de Sistemas / } \\
\text { Programador }\end{array}$ & $\begin{array}{l}\text { Programação em ActionScript } \\
\text { para adequação do material } \\
\text { em FLASH }\end{array}$ \\
\hline
\end{tabular}

\subsection{O roterista ou desenhista instrucional}

Esse profissional pode receber diferentes designações, mas cabe a ele a tarefa de planejar e desenvolver o desenho instrucional de aulas Web. Ele será capaz de, valendo-se de criatividade e competência acadêmica na área, fazer roteiros (storyboard) incluindo aí elementos facilitadores de aprendizagem, tais como vídeos, animações, desenhos e textos, tudo isso da forma mais didática e sintética possível. É importante que este profissional tenha algum conhecimento da legislação de direitos autorais para evitar conflitos de interesses. O domínio do idioma inglês e de técnicas pedagógicas 
de Ensino a Distância são essenciais, visto que, na Biologia, a literatura específica é na grande maioria escrita em inglês. Deve ter disponibilidade e boa vontade para auxiliar no treinamento e na capacitação de novos roteiristas. O domínio dos programas como Word, Excel, internet, correio eletrônico e conhecimentos básicos de Flash são muito desejáveis.

Perfil do desenhista instrucional na Web da Fundação: Escolaridade: mestrado ou doutorado, criatividade, espírito de equipe, bom humor, responsabilidade e respeito ao planejamento anual de atividades.

\subsection{Webdesigner (animador)}

O profissional que prepara as animações que foram roteirizadas pelo desenhista instrucional utiliza com total domínio o programa Adobe Flash ou outra ferramenta de animações e ilustrações, com velocidade no preparo das animações. A capacidade de preparar jogos e exercícios usando o ActionScript se faz de grande utilidade. Também é desejável que possua domínio de alguma ferramenta para executar animações em 3D, com velocidade e qualidade (ex: 3Ds MAX). Os melhores profissionais da equipe são convidados a ministrar aulas para os demais componentes do grupo sobre as ferramentas descritas, de modo que todo o grupo evolui com o passar do tempo, aumentando enormemente a qualidade do trabalho e a interação entre os membros do grupo.

Perfil do animador: possuir ensino médio completo e domínio dos seguintes programas: Flash/Photoshop/Software de ilustração vetorial/ActionScript/ Software 3D/Corel.

\subsection{Webdesigner (HTML)}

Um segundo profissional webdesigner é aquele que, diferentemente do animador, se dedica à criação $e$ produção de layouts para websites. É muito importante que possua conhecimentos em Flash, Photoshop, Dreamweaver, Corel Draw e PHP, além de experiência com projetos de webdesign, criação para internet, preparo de interfaces para sistemas e aplicações multimídia. É este profissional que dá suporte à equipe de programação para a parte de design.

O perfil adequado de webdesigner (HTML) é aquele profissional com domínio dos seguintes programas: pacote Adobe Flash / Photoshop / Software de ilustração vetorial / ActionScript / Corel/ HTML.

\subsection{Ilustrador}

No preparo das aulas para a Web se faz necessária a produção de desenhos originais para esquemas de eventos biológicos, bem como de figuras humanas, animais e plantas. Desse modo, é indispensável a presença de um ilustrador, que promoverá a interface com os demais membros da equipe. Sua função primordial será a de produzir ilustrações originais e, desejavelmente, animações utilizando o programa Adobe Flash. Também caberá ao ilustrador promover o tratamento visual das imagens, criar personagens e ter domínio da técnica de desenho à mão livre e pintura para a produção de material multimídia para EAD. É indispensável o domínio da técnica de desenhos com mesa digitalizadora (tablet).

O perfil desejável para o ilustrador inclui o domínio dos seguintes programas: Flash / Photoshop / Software de ilustração vetorial/Corel Draw.

\subsection{Revisor de português}

É de extrema importância que haja o perfeito uso da língua portuguesa nos textos, legendas e balóes que farão parte do material de aulas para a Web. Desse modo, a contratação de um revisor se faz indispensável. Além de possuir sólidos conhecimentos da língua portuguesa, de preferência com pós-graduação em Letras, deve ser experiente em revisão de textos e ter domínio do Flash, uma vez que as correções deverão ocorrer dentro das animações no programa Flash. É necessário um treinamento para se adequar à linguagem Web uma vez que os textos para material impresso normalmente não se aplicam a multimídia. A escolaridade mínima para esta função é graduação em Letras. O perfil desejável é que possua domínio dos programas: Word, internet, correio eletrônico e conhecimentos básicos de Flash.

Na nossa equipe, damos o treinamento em correção de textos usando o Flash. Selecionamos novos revisores dando um teste para correção, em que se incluem, além de erros ortográficos, erros de expressão, repetições desnecessárias, mau-uso de expressões, entre outras irregularidades indesejáveis para uma compreensão rápida e leve dos conceitos biológicos. 


\subsection{Analista de sistemas / Programador}

No preparo de aulas Web, necessário se faz o profissional analista de sistemas ou programador. Deve dominar a programação em ActionScript para adequação do material em Flash. É desejável, embora não obrigatório possuir o Ensino Superior.

Caberão ao programador a análise e o desenvolvimento de sistemas de pequena e média complexidades, além de realizar manutenção, aperfeiçoamento de sistemas e domínio das linguagens PHP, ActionScript (Flash) e Java para internet. Também a manipulação e gestão de bancos de dados e domínio dos SGBDs MySql e Postgres. O domínio da linguagem de consulta a bancos de dados SQL e a criação de elementos internos deste em outras linguagens de programação são também realizados pelo programador. Este profissional deve zelar para o bom funcionamento dos servidores e sistemas do setor, bem como a previsão $e$ acertos de possíveis falhas, além da manutenção $e$ backup de bancos de dados e sistemas junto a outras equipes da instituição.

O perfil desejável é o domínio das linguagens de programação: PHP, ActionScript (Flash) e Java.

\section{Do material permanente}

\subsection{Computador}

A configuração mínima de hardware utilizada pelos webdesigners (animadores) é a de um microcomputador com processador Intel Core 2 Duo E-4600, com 4gb de memória ddr2 800, placa-mãe para processador Intel, HD de 80gb sata2, hd de 250gb sata2 e gravador de DVD, teclado e mouse óptico. Os programas inseridos são: Windows XP, Autodesk 3Ds MAX, Adobe Flash CS3, Poser, e outros softwares.

\section{Plataforma}

A plataforma é o local onde todo o conteúdo do curso, assim como o material multimídia, é disponibilizado para o aluno. Este ambiente é como se fosse o "Campus da Universidade Virtual" onde o aluno tem acesso às aulas, download de arquivos, quadro de avisos, etc. A nova plataforma CEDERJ utiliza o Sistema Quantum 3.0. Neste sistema, o professor tem condições de apresentar suas aulas para estudo online ou offline, administrar seus cursos, apresentar ques- tões para avaliação, orientar seus alunos utilizando ferramentas de comunicação, tais como: e-mail, chat, fórum, mural, FAQ (perguntas mais frequentes), "tira" dúvidas, colaboração etc. A plataforma obedece ao padrão internacional do W3C (World Wide Web Consortium) que estabelece as diretrizes técnicas a serem adotadas para a acessibilidade na Web.

\section{Resultados e discussão}

Atualmente, sabe-se que a compreensão da realidade pode se dar de várias formas e em diferentes graus de complexidade. Sendo assim, se faz necessário avaliar as formas de abordagem dos conteúdos, de forma que seja possível atingir o maior número de indivíduos interessados em aprender (REAL e SOUZA, 2008).

Além dessa pluralidade de formas e complexidade, é importante levar em consideração os diferentes estilos de aprendizagem que um indivíduo pode utilizar. Segundo Felder e Silverman (1988), esses estilos são uma preferência característica e dominante na forma como as pessoas recebem e processam as informações, considerando os estilos como habilidades passíveis de serem desenvolvidas. Alguns indivíduos podem tender a focalizar fatos, enquanto outros podem preferir o aprendizado baseado em teorias. Uns podem responder melhor a estímulos visuais, enquanto outros necessitam de informações verbais, sejam elas orais ou escritas. Há ainda os que possam preferir aprender de forma ativa, interativa, e aqueles que optem por uma abordagem individual, introspectiva.

O desenvolvimento de Tecnologias de Informação e Comunicação (TICs) tem possibilitado o desenvolvimento de cursos de graduação a distância de excelente nível de qualidade e comparável aos melhores cursos presenciais. Essas tecnologias são importantes não só para a comunicação com os alunos, mas também para a produção de material didático aplicado a esses cursos. Assim, buscamos desenvolver um material baseado no uso dessas tecnologias, que possa ser útil na maioria dos estilos de aprendizagem que um indivíduo possa escolher.

O material produzido para as aulas Web do curso de Ciências Biológicas possui características bas- 
tante particulares e busca complementar o material impresso utilizado nas diferentes disciplinas e ser um potente instrumento de ensino-aprendizagem. Por ser um material principalmente voltado para EAD, precisa ser atraente, capaz de prender a atenção do aluno e explicativo por si só. É importante lembrar que como o aluno está a distância, o professor não está presente para estimulá-lo e mantêlo concentrado no estudo e nem para fornecer explicações imediatas sobre o conteúdo apresentado. Desse modo, não pode gerar dúvidas, nem de navegação nem de conteúdo. Além disso, deve manter o aluno ocupado, interagindo com a tela e não um simples espectador como ocorre, por exemplo, quando se assiste a um filme.

Dentre as características principais do material podemos citar: o controle de navegação por parte do aluno, congregação de diferentes recursos audiovisuais, linguagem adaptada, aproximação com o cotidiano do aluno, humanização, humor, uso de analogias e ludicidade na explicação de conceitos e a concretização do abstrato.

No nosso trabalho, são produzidas animações utilizando o que há de mais moderno em tecnologias e mídias de animações 2D e 3D como Autodesk 3Ds MAX, Cinema 4D, Hexagon, Maya, Poser, e outros softwares que geram objetos importados para o Adobe Flash CS3 que é o arquivo final da animação, gerenciada por páginas em HTML. Todos os vídeos e animações $3 \mathrm{D}$, antes de serem importados, são convertidos em formato de arquivo FLV (Flash Vídeo). É um dos formatos de arquivo mais populares encontrados na internet devido à qualidade $e$ serem geralmente muito pequenos.

\subsection{Estrutura de uma aula \\ 5.1.1. O vídeo de apresentação}

Todo o material possui uma identidade em termos de estrutura (Figura 1). No primeiro momento, o aluno tem a possibilidade de assistir a um pequeno vídeo de apresentação do conteúdo. Neste vídeo, gravado por um professor, são mostrados os principais pontos da aula e, de certa forma, tem o objetivo de humanizá-la, pois o aluno "verá" o rosto de um professor, e também de fazer com que o aluno se interesse pelo conteúdo que será apresentado (Suplemento 1)*.

\subsubsection{Objetivos e pré-requisitos}

O tema da aula é apresentado sob a forma de uma bela animação, que finaliza com a entrada dos objetivos e pré-requisitos da aula (Suplemento 2).

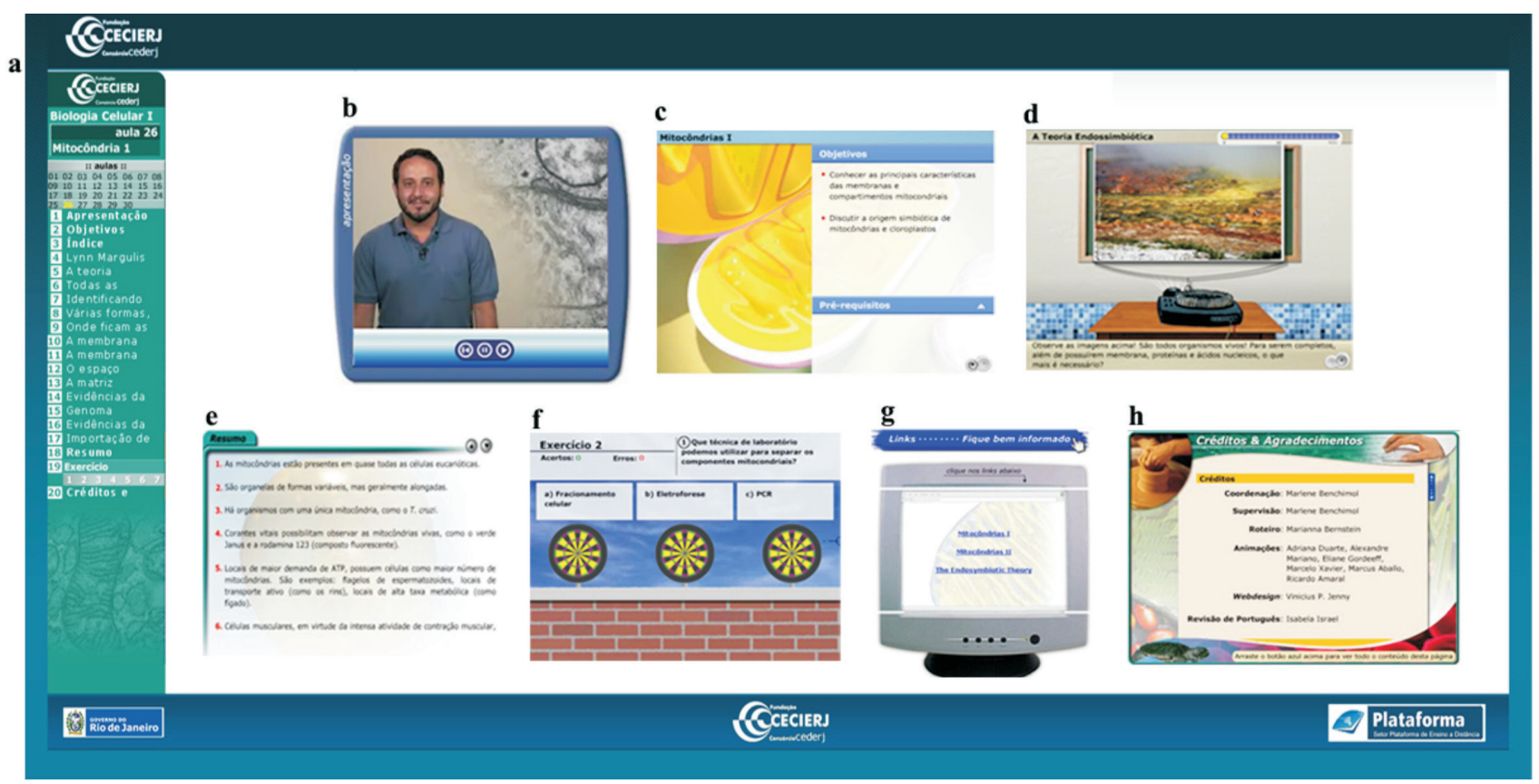

Figura 1: Exemplo da estrutura de uma aula Web. Em (a), barra de navegação da plataforma (ou CD); (b) vídeo de apresentação; (c) objetivos e prérequisitos; (d) animações de conteúdo das aulas; (e) resumo; (f) página de links externos; (g) exercícios; (h) créditos e agradecimentos.

* Os suplementos são hiperlinks dos arquivos multimídia disponibilizados no sítio da revista 


\subsubsection{A aula propriamente dita}

O corpo da aula é formado por animações, simuladores, objetos de aprendizagem que conduzam o aluno ao entendimento de conceitos importantes daquele assunto em questão. $\mathrm{O}$ aluno interage e tem a possibilidade de ficar o tempo que desejar em cada "página" de tela. O processo é interativo.

\subsubsection{Exercícios}

Ao final do conteúdo da aula, são apresentados exercícios que têm por finalidade: (1) fixar o assunto, (2) verificar a aprendizagem, (3) reforçar conceitos importantes. Os exercícios também são apresentados sob a forma de animações, mas principalmente sob a forma de jogos, tais como dominó, forca, boliche, etc., em que à medida que o aluno acerta, ocorre a pontuação $e$ a resposta certa, possibilitando o imediato feedback (Suplemento 3).

\subsubsection{Resumo da aula}

Ao final da sequência de animações, o aluno pode acessar um resumo do conteúdo em tópicos sobre os principais conceitos apresentados na aula, uma página com links externos para aprofundamento de conteúdo e exercícios para fixação e aplicação dos conceitos aprendidos.

\subsubsection{Créditos e agradecimentos}

Por fim, são apresentados os créditos da equipe envolvida na produção da aula $e$ os agradecimentos a pessoas e instituições que contribuíram com imagens e vídeos. Todo material utilizado nas aulas obedece ao licenciamento do Creative Common com restrições, tais como: são livres para cópia desde que citada a fonte e sem fins comerciais, nem alteração de conteúdo.

\section{Layout de tela}

O layout de tela é apresentado de forma bem simples, valorizando o espaço destinado à apresentação dinâmica do conteúdo. A Figura 2 mostra como as telas são organizadas.

Na parte superior à esquerda, é apresentado o título da animação e à direita uma barra de controle de navegação. Deste modo, o aluno pode se situar dentro do conteúdo da aula e também controlar o seu progresso dentro da animação.

\section{Barra de título}

\section{Barra de navegação}

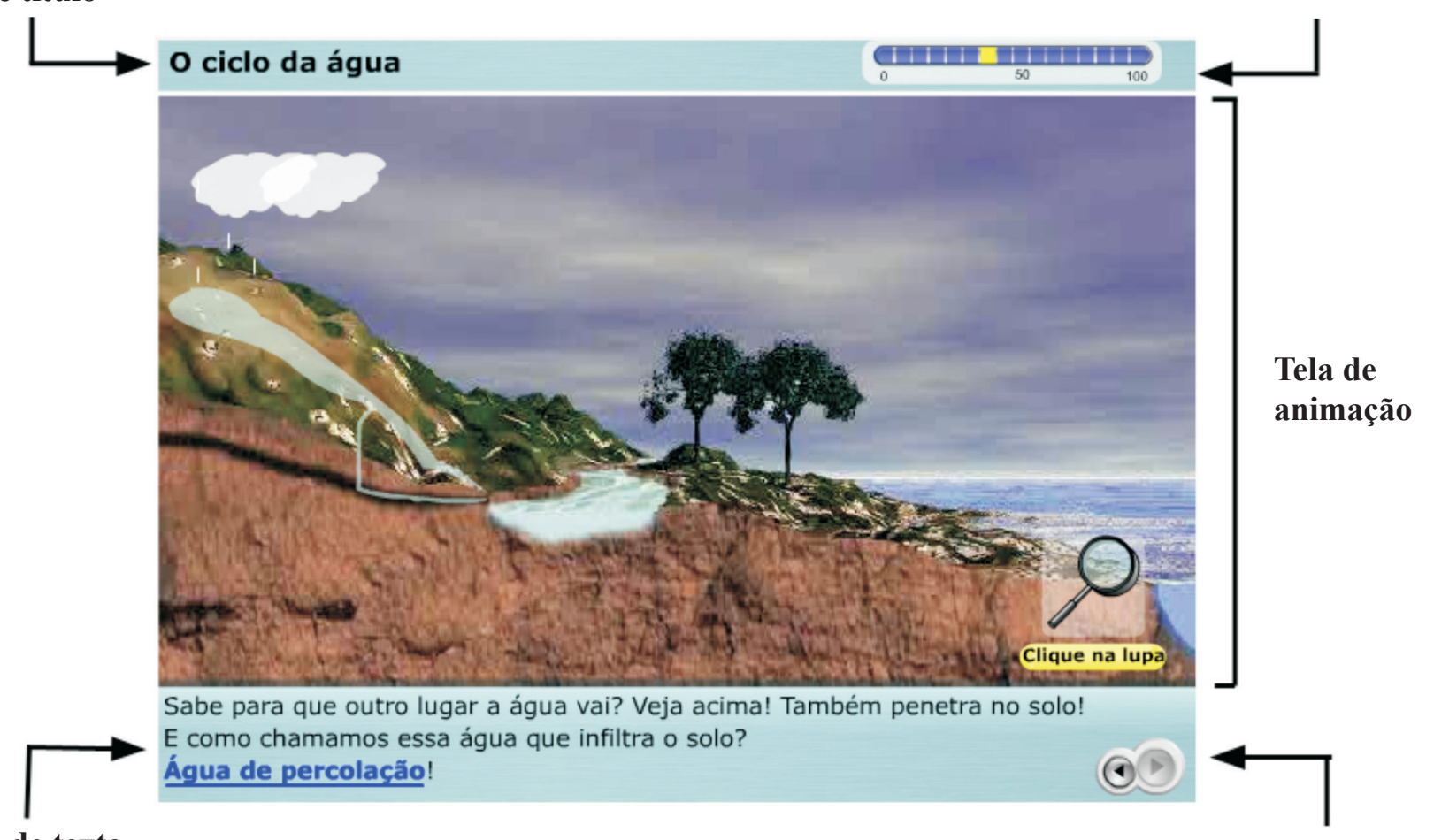

\section{Barra de texto}

Botões de navegação

Figura 2: Layout de tela - imagem do padrão de tela utilizado nas aulas Web. Na parte superior encontram-se: à esquerda, o título da animação; à direita, a barra de controle de navegação. No centro, há o espaço destinado à animação propriamente dita. Na parte inferior, temos a barra de texto e os botões de navegação (à direita). 
O centro da tela é destinado à apresentação do conteúdo sob a forma de diferentes recursos audiovisuais. Quando há necessidade de interação do aluno com o material, como, por exemplo, passar o mouse ou clicar em alguma região da tela, toda e qualquer instrução é passada no lado direito da tela. A entrada de imagens e as principais movimentações em tela ocorrem sempre da esquerda para a direita, obedecendo ao sentido de leitura ocidental (Suplemento 4).

$\mathrm{Na}$ parte mais inferior da tela há a caixa de texto que, em geral, não excede o espaço de cinco linhas. Esses textos buscam apresentar o conteúdo de forma simples e objetiva. Quando há a necessidade de informações adicionais como, por exemplo, definições, traduções de termos específicos, são utilizados recursos de mouse over, quando são abertos pop ups explicativos (Suplemento 4).

No canto inferior direito desta barra de texto encontram-se os botões de navegação da animação, através dos quais o aluno pode avançar ou retroceder naquela animação.

\section{Ferramentas de navegação}

Ao longo das animações, utilizamos ferramentas de navegação padronizadas, de modo que quando visualizadas pelo aluno ele saiba o que fazer e o que poderá encontrar com sua utilização (Suplemento 5).

\section{Recursos audiovisuais}

A Biologia é uma Ciência que nos fornece uma ampla variedade de imagens, sons, cores, estruturas, estímulos. Portanto, a utilização de recursos audiovisuais variados torna o material rico, dinâmico e capaz de mostrar ao aluno a realidade da Ciência.

As animações são o corpo principal do material produzido e são responsáveis por apresentar o conteúdo de forma dinâmica. Constituem, em sua grande parte, objetos de aprendizagem (OA). Esses objetos são construídos de forma a contemplar objetivos específicos do conteúdo, sendo possível o seu reaproveitamento em outras aulas.

Na maioria das vezes, as animações contribuem para a concretização do abstrato. É possível visualizar, por exemplo, os diferentes passos de uma reação química, compreender como ocorre a síntese de proteínas, a duplicação do DNA. São utilizados recursos de interatividade de modo que o aluno se sinta parte integrante do processo (Suplemento 6).

Os vídeos trazem para o aluno a possibilidade de ter o contato com o real, avaliar determinados comportamentos dos organismos, observar a execução de uma atividade prática, etc. (Suplemento 7).

As fotos, da mesma maneira que os vídeos, apresentam a Ciência de forma real. Em muitos casos, precedem esquemas explicativos. São de grande importância no ensino de Biologia uma vez que, nem sempre, o aluno terá a possibilidade de visualizar imagens em microscópios, organismos e estruturas anatômicas como realmente são (Suplemento 8).

Como a Biologia envolve muita experimentação, as simulações de atividades práticas consistem em uma boa ferramenta para o ensino. Através desse material, o aluno pode ter ciência das etapas a serem cumpridas, dos fenômenos que podem ser observados ao longo de um experimento e também da base teórica para interpretação de resultados (Suplemento 9).

\section{A linguagem nas aulas Web}

O material na Web faz, na maioria dos casos, o papel do professor presencial. Então, a linguagem desse material precisa ser diferente daquela observada nos livros-texto. Piaget (1976) afirma que a inteligência humana somente se desenvolve no indivíduo em função de interações sociais. Então, a reciprocidade de pensamento entre os interlocutores é condição para a construção do conhecimento.

Complementando este pensamento, Bakhtin (2002) propõe que o dialogismo estabelece a interação verbal no centro das relações sociais. Sendo assim, é possível avaliar a importância da ação verbal (linguagem) como parte essencial de uma interação. Dentro desta ótica, a linguagem é vista como instrumento de interação social e formadora de conhecimento (REAL e SOUZA, 2008).

Por isso, é preciso questionar, levar o aluno a pensar sobre o conteúdo que está sendo aprendido e não dar o conhecimento pronto, fechado. O próprio aluno deve participar desse processo construtivista. Os conteúdos impressos são, em geral, extensos e pesados enquanto que a proposta do nosso material é facilitar o entendimento dos pontos principais. Assim, buscamos sempre 
utilizar textos curtos, remetendo sempre que possível ao que está acontecendo na parte central da tela.

Desta forma, o aluno é levado a observar, a extrair de uma imagem (ou de um vídeo, ou de uma animação) a sua essência. A Figura 3 mostra um exemplo dessa adaptação de linguagem.
Para que o aluno possa construir o seu conhecimento é preciso que o conteúdo seja apresentado aos poucos, sempre questionando, dialogando, fazendo com que cada detalhe seja percebido e bem compreendido. Por isso, os eventos são mostrados em partes e o aluno controla a navegação. Também são utilizados recursos inte- a

- O código genérico é degenerado. Existem 64 combinações possíveis de três nucleotídeos, ainda que apenas vinte aminoácidos participem da síntese de proteínas. Esta discrepância pode ser explicada porque existe certa redundância na tradução. Em outras palavras, alguns aminoácidos são especificados por mais de um códon, com apenas metionina e triptofano sendo codificados por códons únicos.

b
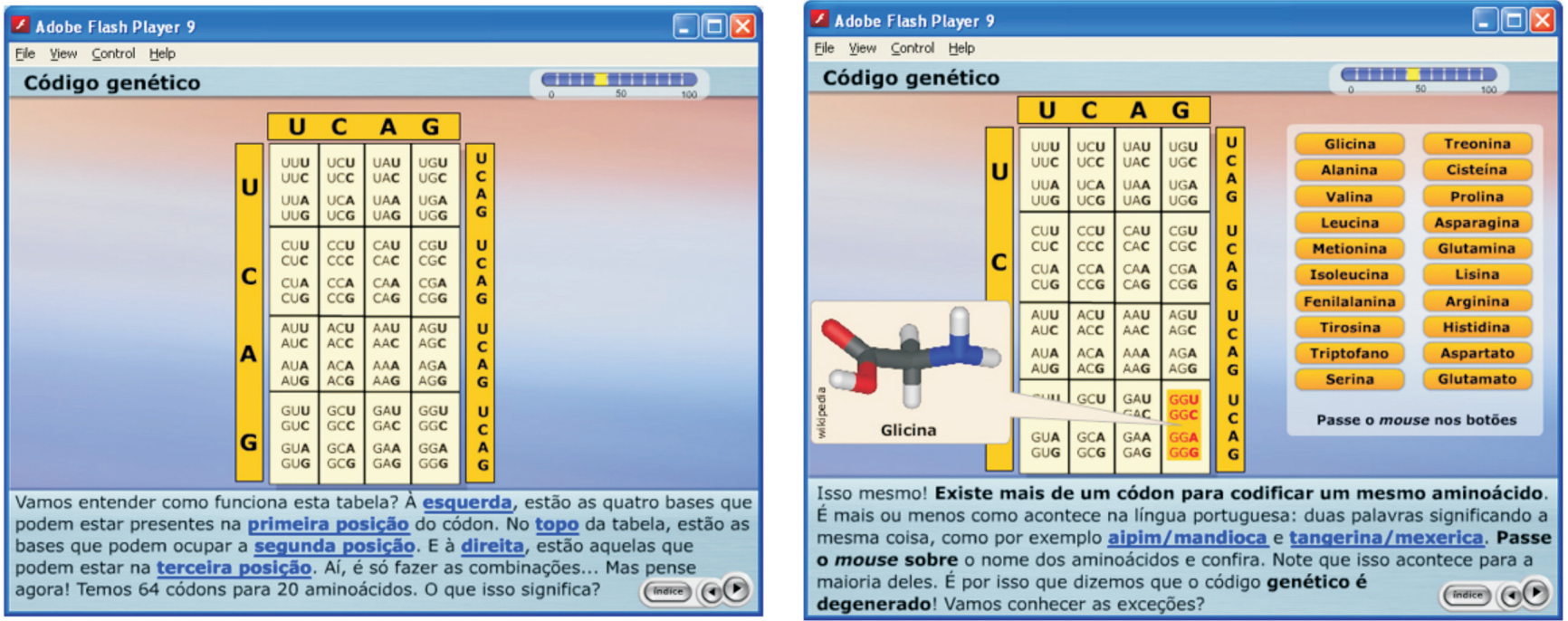

Figura 3: Exemplo de adaptação da linguagem - Em (a), texto extraído do material impresso para o Consórcio CEDERJ, disciplina Biologia Molecular. Em (b), cenas da aula Web correspondentes ao texto, com linguagem adaptada.

rativos para que essa compreensão seja mais efetiva. Por exemplo, a execução de cruzamentos em aulas de $\mathrm{Ge}$ nética. Nestes cruzamentos, são apresentadas as opções de gametas para que o aluno arraste para uma tabela $e$ veja o fenótipo resultante (Figura 4). Assim, ele pode chegar a sua própria conclusão sobre as proporções genotípicas nas diferentes gerações (Suplemento 10).

As aulas da Web procuram, sempre que possível, fazer correlações entre o conteúdo e o cotidiano do aluno. Esta abordagem baseia-se nos princípios de Paulo Freire (1983) e Vygotsky (1989) que vêem o aluno como construtor de seu conhecimento, mas inserido em uma sociedade, em uma cultura que irá determinar esse conhecimento. Assim, o aluno compreende que o seu dia a dia faz parte do conteúdo e todo o conhecimento aprendido poderá ser útil. Um exemplo da correlação com o cotidiano está apresentado na Figura 5. Ao tratar do assunto sobre fungos parasitas, o aluno é remetido a experiências conhecidas como as micoses de praia, o sapinho e outras doenças comuns e bem conhecidas (Suplemento 11). Assim, além de passar os conceitos relacionados aos fungos parasitas, pode-se também derrubar preconceitos sobre quando as doenças aparecem, como aparecem etc.

Falando em preconceito, todo o material produzido é elaborado tomando os devidos cuidados quanto a situações que possam ser interpretadas como discriminação de qualquer tipo contra as minorias. 

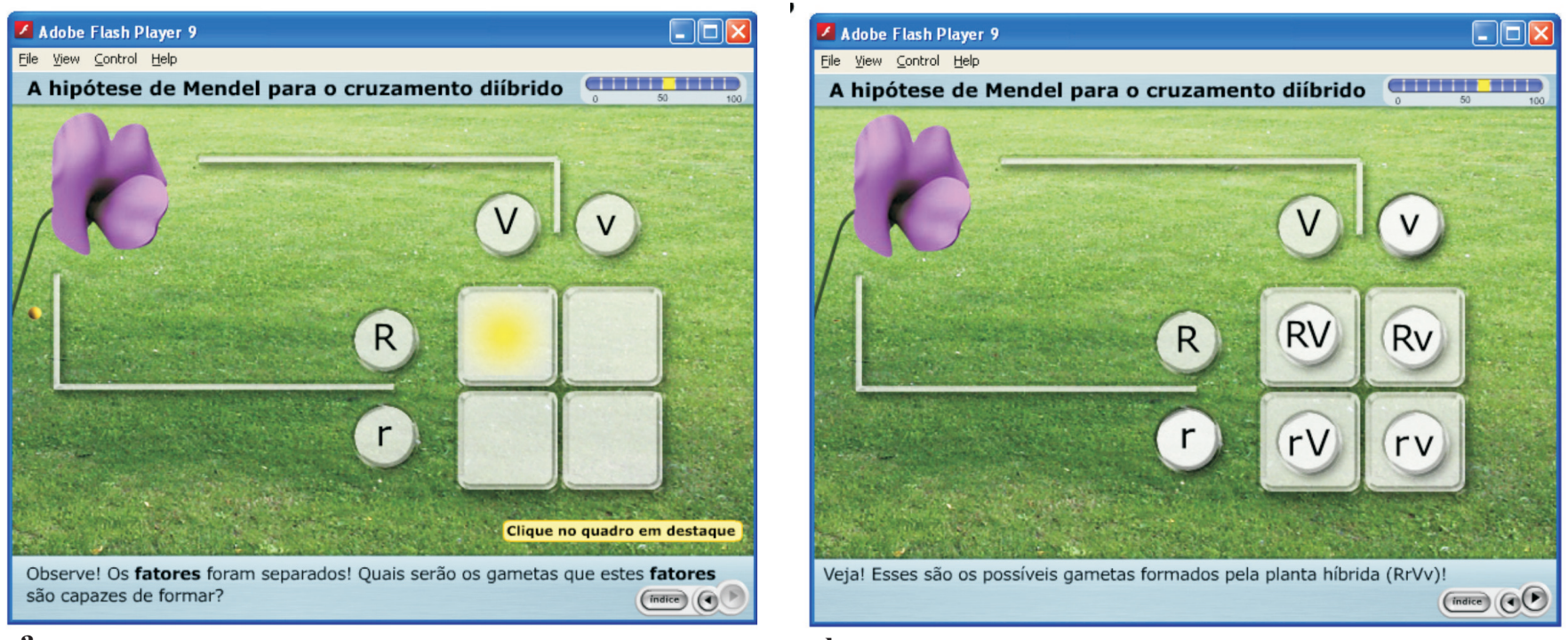

b

Figura 4: Interatividade - Exemplo de cenas que buscam a interatividade do aluno com o material. Material extraído de uma aula Web da disciplina Genética Básica. Em (a), a tela onde o aluno recebe a instrução de como deve interagir com o material. Em (b), o resultado da interação.

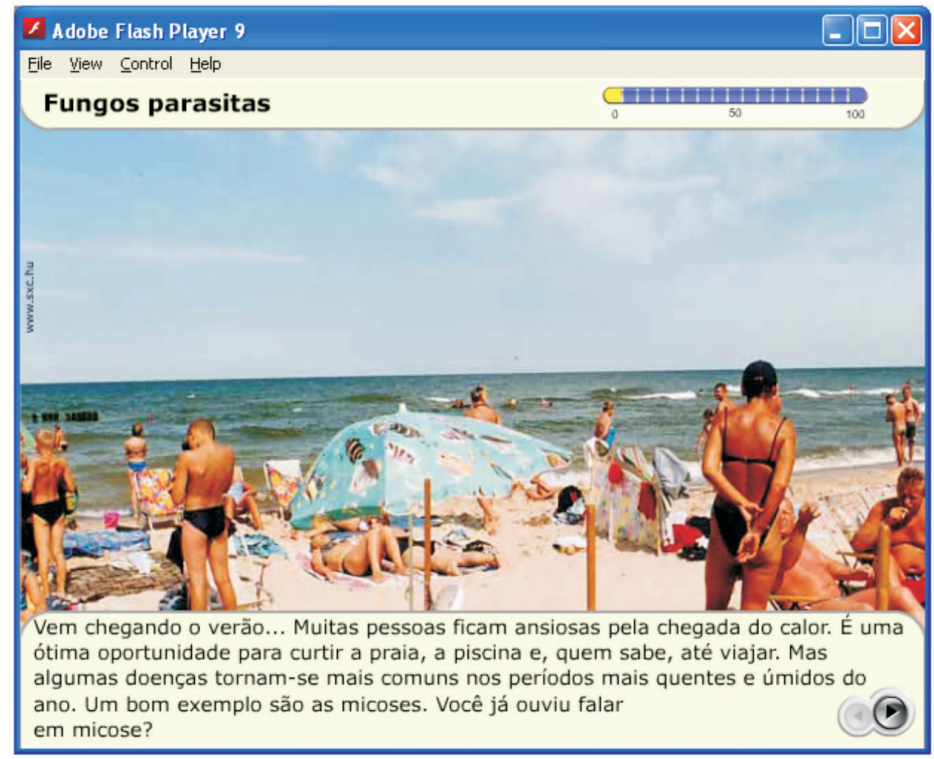

Figura 5: Uso do cotidiano nas aulas Web - Exemplo de utilização do cotidiano durante as aulas. Material extraído de uma aula da disciplina Botânica I sobre fungos parasitas.

Muitas vezes, a utilização de um determinado objeto de aprendizagem busca apenas mostrar um evento sem enfatizar a estrutura dos componentes, como, por exemplo, o transporte de moléculas através das membranas e a síntese proteica.

Nesses casos, utilizamos dois recursos principais: o lúdico, onde os componentes são substituídos por personagens, e as analogias, onde utilizamos elementos conhecidos dos alunos para comparar com elementos do conteúdo (Figura 6) (Suplemento 12).

\section{Humanizando e descontraindo o ambiente de aprendizagem}

\section{1. Personagens}

Por ser um material preparado para o ensino a distância, além das adaptações de linguagem é preciso tornar o material agradável de ser assistido, em que o aluno não se sinta sozinho e que estudar por meio da internet não seja uma experiência monótona. Desta forma, buscamos utilizar animações com elementos personificados como, por exemplo, células, moléculas 
a
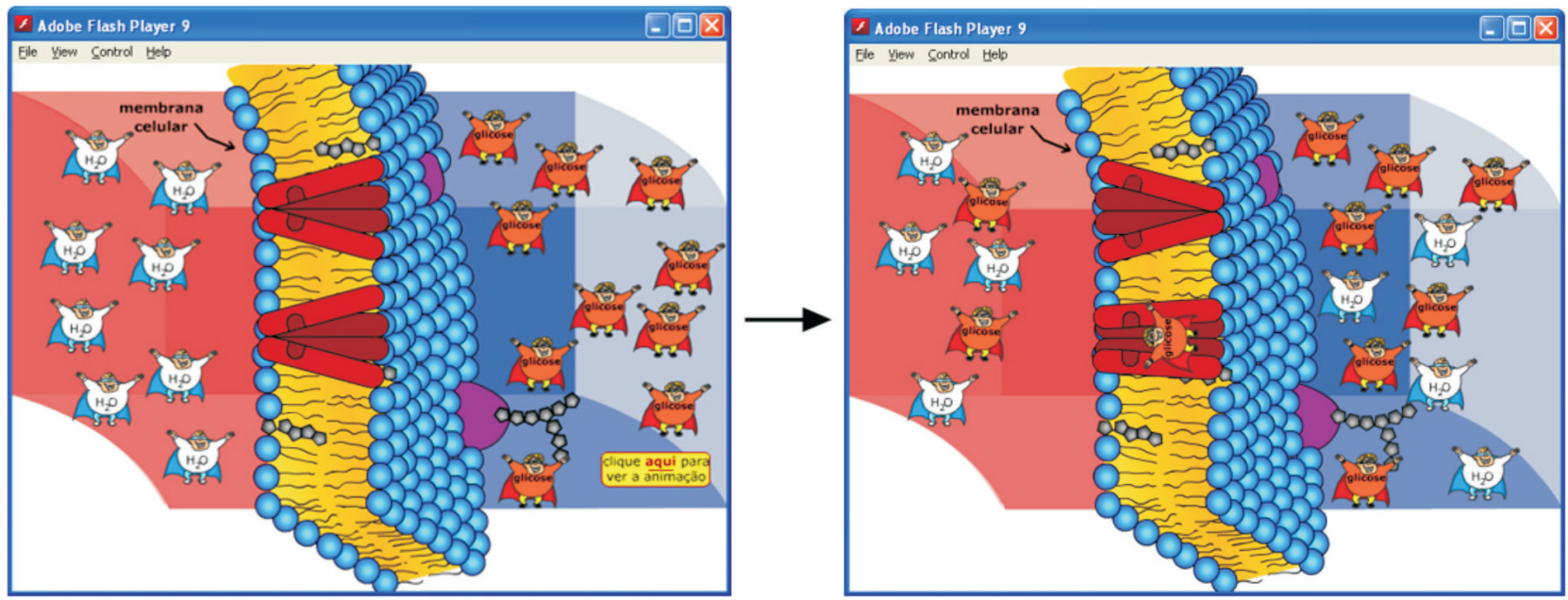

b
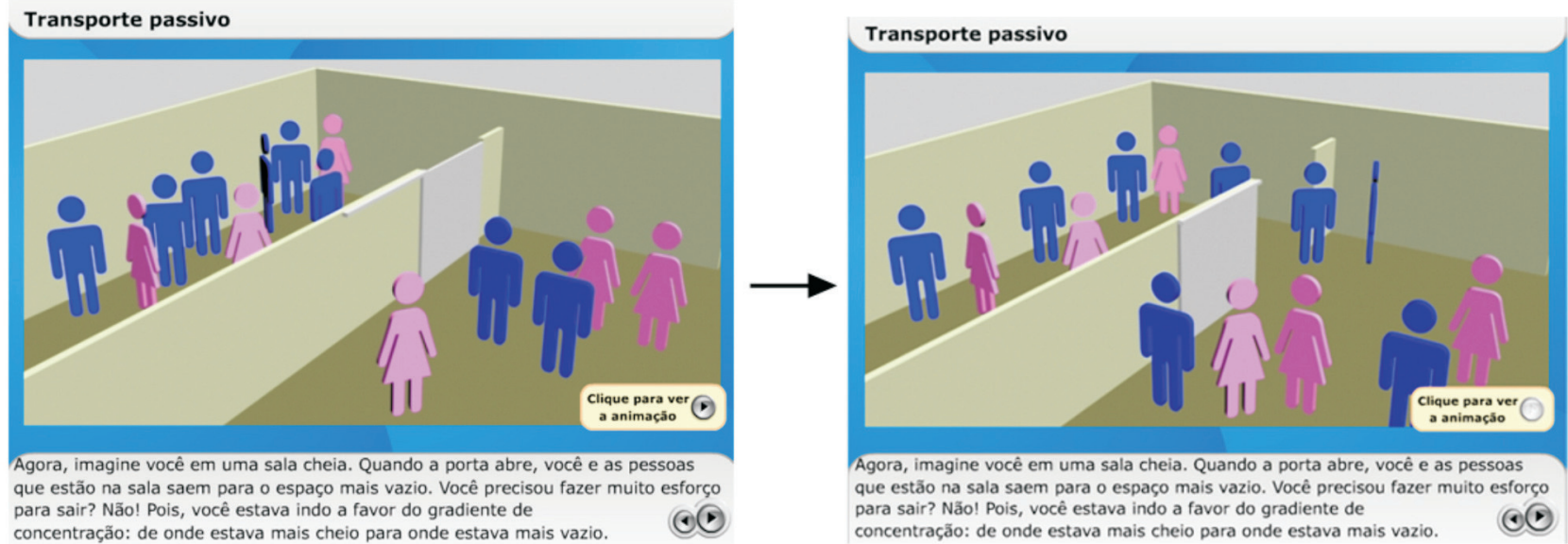

Figura 6: Trabalhando com o lúdico e analogias - Exemplos da utilização do lúdico (a) e de analogias (b). Em (a) a representação do transporte de glicose através da membrana. As moléculas foram substituídas por personagens. Em (b), analogia para explicação do conceito de transporte passivo.

e bactérias falantes e cientistas que apresentam seus próprios trabalhos. A Figura 7 mostra alguns exemplos desse tipo de abordagem (Suplemento 13).

\section{2. O humor nas aulas Web}

O bom humor é sempre mantido em nossas aulas, de maneira que o aluno estude por meio de um conteúdo leve e agradável (Suplemento 14).

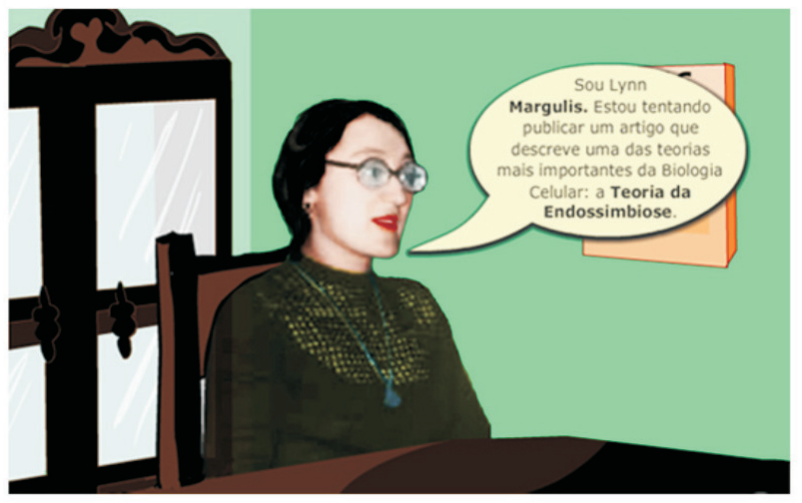

\section{1. Áudio}

\subsection{Narração}

As animações mais recentes possuem áudio apresentando a explicação de cada processo e também do texto. $\mathrm{O}$ aluno tem a opção de controlar a animação habilitando ou desabilitando a narração, podendo prosseguir ou retornar a qualquer parte da animação. A narração do áudio é feita por alguns

b

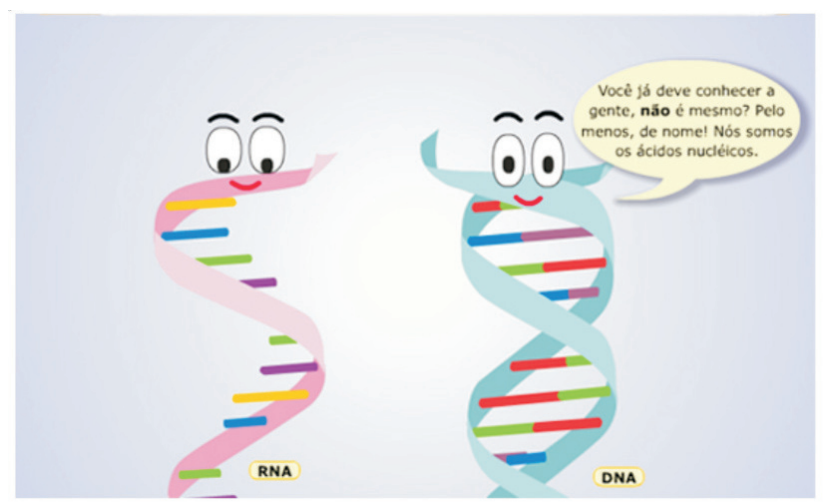

Figura 7: Humanização - exemplo da humanização nas aulas Web. Em (a), o pesquisador se apresenta e fala sobre o seu próprio trabalho. Para este tipo de material são utilizados recursos de animação do software Crazy Talk. Em (b), as moléculas de DNA se transformam em personagens que apresentam o conteúdo. 
funcionários da própria equipe que participaram do curso de "Performance em Câmera". A voz da narração deve ser clara e agradável e ter personagens masculinos e femininos. A gravação do áudio é realizada em estúdio e os arquivos são gravados em 16bits mono WAV com uma frequência de $48000 \mathrm{kHz}$ usando o programa Adobe Premiere.

\subsection{Fundo musical e sonoplastia}

Tanto a abertura da aula, como eventos que ficam mais marcantes se houver sons para canto e ruídos de animais, bem como fundo musical, são sempre utilizados, quando isso é possível. Ficamos atentos aos direitos autorais de músicas, usando sempre músicas e sonoplastia permitidas. Tanto os recursos de sonoplastia como de sonorização de fundo devem contemplar músicas suaves e agradáveis (Suplemento 15).

\section{Publicação dos conteúdos multimídia em CD-ROM}

Todo o material produzido passa por uma revisão de língua portuguesa e por uma revisão de conteúdo. Esta última é feita por pesquisadores conceituados das áreas específicas da Biologia (adhocs). Finalizado o processo de revisão, o conteúdo das disciplinas, inicialmente disponível na World Wide Web para os alunos matriculados no curso de Biologia do CEDERJ, é publicado em CD-ROM com ISBN. A reprodução deste material para educação sem fins comerciais $e$ sem alterações da obra original é permitida desde que citada a fonte, obedecendo assim os preceitos do Creative Commons. O CD-ROM foi desenvolvido para funcionar em um computador com os requisitos mínimos de sistema recomendados: Microsoft Windows XP, Internet Explorer 6 ou Firefox versão 3, Flash Player 8, processador Pentium com 512 de memória e leitor de CD-ROM.

A grande vantagem da geração do CD-ROM é a possibilidade de um maior acesso dos alunos às aulas multimídia produzidas em nosso setor, uma vez que a sua visualização independe da conexão à internet.

\section{Considerações finais}

Neste trabalho demonstramos as etapas utilizadas para a produção de material didático multimídia des- tinado aos alunos do curso de graduação em Ciências Biológicas do consórcio CEDERJ. Não obstante, é importante salientar que a equipe WebBiologia é uma equipe dinâmica, caracterizada pela sua renovação e desenvolvimento constantes, que busca incessantemente o aperfeiçoamento do seu pessoal e do material desenvolvido, com o intuito de alcançar os objetivos educacionais e de ampliar as possibilidades de difusão do conhecimento.

Nossa experiência tem demonstrado que os objetos de aprendizagem produzidos para as aulas Web do curso de Ciências Biológicas, além de peculiares, representam potentes instrumentos auxiliadores do processo de ensino-aprendizagem.

O trabalho apresentado pela equipe WebBiologia é motivo de muito orgulho e satisfação e tem sido recebido com bastante interesse por educadores provenientes de outras instituições, tanto nacionais quanto internacionais, que nos procuram frequentemente a fim de trocar experiências acerca do desenvolvimento do material multimídia.

O próximo desafio é testar a eficiência e a eficácia das diferentes formas de apresentação do conteúdo produzidas pela equipe, com a finalidade de traçar o perfil ideal de transmissão do conhecimento através dos objetos de aprendizagem multimídia.

\section{Agradecimentos}

- FAPERJ (Fundação de Amparo à Pesquisa do

Estado do Rio de Janeiro)

- Fundação CECIERJ

- Equipe de animadores e webdesigners da WebBiologia 


\section{Referências bibliográficas:}

BAKHTIN, Mikhail. Marxismo e filosofia da linguagem. São Paulo: Hucitec, 2002

BUCKLEY, Barbara C. Interactive multimedia and model-based learning in biology. International Journal of Science Education, v. 22, n. 9, p. 895-935, 2000.

FELDER, Richard M.; SILVERMAN, Linda K. Learning and teaching styles in engineering ducation. Engr. Education, v. 78, n. 7, p. 674-681, 1988. Disponível em: <http://www4.ncsu.edu/unity/ lockers/users/f/felder/public/Papers/LS-1988.pdf > Acesso em: 22 set. 2009.

FERK, Vesna; VRTACNIK, Margareta; BLEJEC, Andrej; GRIL, Alenka. Students' understanding of molecular structure representations. International Journal of Science Education, v. 25, n. 10, p. 1227 1245, 2003.

FREIRE, Paulo. Educação como prática da liberdade. Rio de Janeiro: Paz e Terra, 1983.

LÉVY, Pierre. Cibercultura. São Paulo: Ed. 34, 1999.

MATHEWSON, James H. Visual-spatial thinking: An aspect of Science overlooked by educators. Science Education, v. 83, n. 1, p. 33-54, 1999.

MAYER, Richard E.; BOVE, William; BRYMAN, Alexandra; MARS, Rebecca; TAPANGCO, Lene. When less is more: Meaningful learning from visual and verbal summaries of science textbook lessons. Journal of Educational Psychology, v. 88, n. 1, p. 64-73, 1996.

PEECK, Joan. Increasing picture effects in learning from illustrated text. Learning and Instruction, v. 3, p. 227-238, 1993.

PIAGET, Jean; INHELDER, Bärbel. Da lógica da criança à lógica do adolescente. São Paulo: Pioneira, 1976.
REAL, Conceição M.C.R.C.; DE SOUZA, Carlos H.M. Reflexões sobre a linguagem como atividade sociocognitiva adjuvante no processo educacional. Inter Science Place, v. 1, n. 3, p. 1-11, 2008.

ROBERTS, Judith $M$. The story of distance education: A practitioner's perspective. Journal of the American Society for Information Science, v. 47, p. 811-816, 1996.

ROTH, Wolff-Michael; BOWEN, Michael G.; MCGINN, Michelle K. Differences in graph-related practices between high school biology textbooks and scientific ecology journals. Journal of Research in Science Teaching, v. 36, n. 9, p. 977-1019, 1999.

SANGER, Michael J.; BRECHEISEN, Dorothy M.; HYNEK, Brian M. Can computer animations affect college biology students' conceptions about diffusion \& osmosis? The American Biology Teacher, v. 63, n. 2, p. 104-109, 2001.

SIEAD. Sistema de consulta de instituições credenciadas para educação a distância e polos de apoio presencial. Disponível em: <http://siead.mec.gov.br/novosiead/> Acesso em: 21 set. 2009.

VYGOTSKY, Lev Semenovitch. A formação social da mente. São Paulo: Martins Fontes, 1989. 